\title{
The Impact of the 4th Industrial Revolution on SMEs' High-Tech Industry*
}

\author{
Sandro Trento**, Mariasole Bannò***, \\ Giorgia M. D'Allura****
}

\begin{abstract}
The goal of this paper is to investigate the transformation of business models in the fourth industrial revolution in the manufacturing industry considering the production chain relationships of small and medium enterprises (SMEs). We aim to investigate whether and how the challenges of I40 entail new business models to improve customer value creation. How do manufacturing SMEs perceive the I4O phenomenon? How do manufacturing SMEs innovate their business models because of I40? How do manufacturing SMEs behave with their suppliers because of I40? How do manufacturing SMEs behave with their customers because of I40?
\end{abstract}

Keywords: Internet of Things; Technological Change; Industry 4.0; Business Models; Process Innovation; High-Tech Industry; Global Competition.

\section{The Fourth Industrial Revolution in the Manufacturing Industry}

The goal of this paper is to investigate the transformation of business models as a consequence of the fourth industrial revolution (I40) in the manufacturing industry considering the production chain relationships of small and medium enterprises (SMEs). I40 focuses on the role of digital technology in the creation of intelligent products and production processes with digital enhancement or even the reengineering of products and services. Specifically, the fourth industrial revolution implies a deep transformation in the way production takes place, whereby traditional manufacturing plants are replaced by smart factories based on communication between humans, machines and products through the implementation of Cyber Physical Systems (CPS) for industrial production. CPS are networks of microcomputers, sensors, and actuators that can be embedded in materials, devices or machines, and are connected through the internet along the value chain (Porter $\&$ Heppelmann, 2014; Rudtsch et al., 2014).

Firms in the manufacturing industry today must deal with rapid product development, flexible production, and complex and global environments (Bannò et

\footnotetext{
* The Authors: G. D’Allura $\S \S 1,2$, M. Bannò $\S \S 3,4$, S. Trento $\S 5$.

**Full Professor of Management, University of Trento (sandro.trento@unitn.it)

***Assistant Professor of Applied Economics, University of Brescia (mariasole.banno@ unibs.it)

****Assistant Professor of Management, University of Catania (gdallura@unict.it)
} 
al., 2014a; Bannò et al., 2014b; Cappiello, 2016). Based on this evidence, we aim to investigate whether and how the challenges of I40 entail new business models to improve customer value creation.

Extant studies on I40 extensively focus on large enterprises (Arnold et al., 2016; Radziwon et al., 2014) and only marginally on SMEs (Schmidt et al., 2015). Many large firms act as suppliers to SMEs and have SMEs as suppliers, hence the importance of understanding how SMEs implement I40, how this impacts industrial value creation and their role in the value chain.

Therefore, the present paper aims to answer to the following four research questions:

RQ1: How do manufacturing SMEs perceive the I40 phenomenon?

RQ2: How do manufacturing SMEs innovate their business models because of I40?

RQ3: How do manufacturing SMEs behave with their suppliers because of I40?

RQ4: How do manufacturing SMEs behave with their customers because of I40?

Using a qualitative approach, we conduct an explorative case study following indepth interviews with entrepreneurs and managers operating in the high-tech industry (HT). HT industry is typically analogical and is experiencing digitalization only recently. We specifically focus on the HT sector due to its digitalization since the 1980s. The paper is structured as follows. First, we present the theoretical background on business models focusing on production chain relationships in the context of I40. Second, we provide a framework for the analysis, and third we present the empirical results, the implications and conclusions.

\section{Theoretical Background}

\subsection{Industry 4.0}

Industry 4.0 is a term used to refer to the developmental process in the manufacturing process, including the production chain. The term Industry 4.0 was first publicly introduced in 2011 as Industrie 4.0 by a group of representatives from different fields (such as business, politics, and academia) under an initiative to enhance the German competitiveness in the manufacturing industry. The German Federal Government adopted the idea in its High-Tech Strategy for 2020. Subsequently, a Working Group was formed to further advise on the implementation of Industry 4.0.

Therefore, to understand how Industry 4.0 became the fourth revolution, we need to look at how the evolution of manufacturing in the industrial sector has differed in comparison to the past three industrial revolutions. Moreover, we need to consider that revolutions intrinsically refer to an acceleration in the rate of change. But how much change is necessary to be considered a revolution? We should cder that technological change per se is not sufficient to identify an industrial revolution. One key point is that this change has to be permanent and should lead to a new economic trajectory. The second relevant aspect is the link between technological change and organization (Fabiani et al., 2005). Mokyr says that a real industrial revolution consists not just of technological innovations but of such innovations that make an impact at the level of industrial organization (Mokyr, 1997, p.35). 
$\square$ "The First Industrial Revolution (1760-1840). It took place in Britain and introduced machines into production. Manual production was abandoned in favor of the use of steam-powered engines and water as a source of power and was assisted by change in the organization of production from the cottage industry to real manufacturing plants."

$\square$ "The Second Industrial Revolution (1870-1914). It introduced preexisting systems such as telegraphs and railroads into industries. The most relevant change was the introduction of mass production as a primary means to production in general, and the electrification of factories contributed hugely to increasing production rates. The mass production of steel helped introduce railways into the system. Such revolutionary approaches to industry were put to an end with the start of World War I."

"The Third Industrial Revolution (1974 ongoing). Referred to as the digital revolution, the third revolution involved the change from analog and mechanical systems to digital ones. It is a direct result of the huge development in computers and information and communication technology that dramatically reduced the costs of collecting information and coordinating activities within the firm and with outside partners. One implication of this revolution has been a strong trend toward deverticalization and outsourcing."

"The Fourth Revolution. According to experts from industry and research, the upcoming industrial revolution will be triggered by the Internet, which allows communication between humans as well as machines in CPS throughout large networks. It introduces customized and flexible mass production technologies fostering once again novel interaction between technological change and industrial organization. Machines will operate independently or cooperate with humans in creating a customer-oriented production field that constantly works on maintaining itself. The machine rather becomes an independent entity that can collect, analyze, and offer advice based upon data. The idea behind Industry 4.0 is to create a social network where machines can communicate with each other, called the Internet of Things, and with people, called the Internet of People."

\subsection{Business Model}

Over the last 5 years, business model research has been an area of lively discussion and inquiry despite lacking a generally accepted definition (Massa et al., 2017). Business model (hereafter BM) shows how the management of the firm designs and hypotheses about what and how customers want (i.e. value offer), how the firm can organize itself to best meet these needs (i.e. value creation), get paid for doing so, and make a profit (i.e. value capture) (Baden-Fuller \& Haefliger, 2013; Teece, 2010). The BM is made of different components (i.e. revenue, cost, partnerships) (Osterwalder et al., 2005); the central concept is the value proposition that describes 
the drivers of customer value as well as the unique features that firms offer to capture that value (Bouncken \& Fredrich, 2016; Pironti et al., 2015; Rieple \& Pisano, 2015). Value capture (that includes the structure of the costs and the formula of the revenue) defines how firms are compensated by customers (Massa et al., 2017).

From a strategic management perspective, the BM concept generates an understanding of how SMEs can use I40 to provide suitable value offers (and pricing models) to their customers. Considering that the BM concept is intrinsically linked to the exploitation of opportunities (DaSilva \& Trkman, 2014), such as the ones brought by novel technologies (Spieth \& Schneider, 2016), the new contingency created by the I40 calls for BM that have the capacity to collect data from the customer side in order to deliver products better tailored, priced and delivered to customer or segment needs along the entire lifecycle of the product (Kagermann et al., 2013; Porter \& Heppelmann, 2014). In this process, the relationships among SMEs inside the production chain are crucial (Trento, 2005; Tresca, 2013). I40 offers new technologies to make interactions and the $\mathrm{BM}$ can originate new solutions in one of the three business model elements: value creation, value offer and value capture. The analysis of those dimensions of the business model are highly interconnected, so the innovation in one element leads to changes of varying degrees in the other two (Zott \& Amit, 2010). Our observations focus on the interactions among SMEs inside the production chain based on the variation of one of those elements.

\section{Methodology}

\subsection{Research Design and Applicability: Deciding to Use a Case Study Approach}

Qualitative research remains a challenge within I40 business management and the need for this kind of research is evident. A first reason is that I40 requires more explanatory and theory generating research. Qualitative method, in fact, goes beyond the measurement of observable and tries to understand the meaning and beliefs underling action by resolving complex issues that are typical for the fourth industrial revolution.

Qualitative research generally attempts to generate, elaborate, test or induce radical change in theory (Lee et al., 1999; Yin, 1984, 2003; D'Allura, 2015). In our case, the area of research is relatively unknown, and we are engaged in theory-building and theory elaboration types of research that seek to answer how and why questions (Eisenhardt, 1989; Ghauri \& Grønhaug, 2002). As such, we made the choice of performing a case study because we anticipated greater advancement in our understanding of the research phenomenon rather than generalization. We sought to investigate the relevance of I40 and its associated research streams.

The research design is a single-case study but involves numerous levels of analysis. Such design has been preferred over single level case study as it creates more theorydriven variance and divergence in the data that facilitate analytic induction (Pauwels \& Matthyssens, 2004; Bannò \& Zaninotto, 2016).

\subsection{Selecting our Case}

While a research study may investigate I40 at different levels (i.e. workers, firm, industry, and ecosystem), in this paper the research design involves the study of one 
case, as the unit of analysis is the production chain and the relationship among its actors. The central firm is a discrete and easily detected subject that can be analyzed both through its isolated experience in the production chain, and as part of a comprehensive experience of the interviewed firm (i.e. the analyzed firm, its suppliers and customers).

Our sampled firm (and its suppliers and clients) reflects the selection of a specific case from which to induce theory. We selected a high-tech firm that began production in the '80s, SEI Laser. We choose laser technology because it has, among other benefits, an excellent path toward reaching digital production. Thanks to photonics I40 simulation, digital design and real production processes are growing ever closer together. As such, laser technology is the driving force to an increasing extent as demonstrated by its applications: laser tool, cut, solder weld and perforate. The material is processed and removed atom by atom, which in the digital production world of I40 translates to material processing pixel by pixel.

$\square$ "As suggested by Lee et al. (1999) there is no ideal number of cases to identify suppliers' and customers' specificities and we best stop adding cases when little or no incremental learning would occur from more data as we are observing phenomena seen before (i.e. theoretical saturation). The final setting is seven firms in three different points of the production chain."

\subsection{Analyzing the Case Study}

As in typical inductive research, we synthesize cases, and to avoid errors arising from halo effects and other interpretation biases (Strauss \& Corbin, 1998), the transcribed notes were used by a subset of team members (including at least one team member not present at the interviews) to establish a preliminary framework. We followed an iterative process of marking quotes and concepts and reviewing our notes to identify patterns or themes across interviewees.

The first step of our analysis was detailing the firm's individual case history by writing chronologies of the organization (Eisenhardt \& Graebner, 2007). Thus, we are able to track the phenomenon of I40 as it truly is, whether an evolution or disruptive process over time. In the second step the data were rearranged into a conceptual order searching for common and conflicting themes. In the third step, we made cross case analyses through suppliers, firms and customers as suggested by Eisenhardt (1989) and Miles and Huberman (1994) to discover regularities and patterns. We also analyzed data by various sources. At the end of the third step, theoretical constructs and tentative propositions (i.e. a framework) are developed both considering existing literature but also looking for unexpected processes.

\subsection{Data Sources and Collection}

Our study involves data collection through multiple sources including in-depth interviews and written reports (e.g. financial reports, archives, press, budget, market and competition reports).

The primary rich source of data was face to face in depth semi-structured interviews that facilitated a free expression of the informants' ideas. We planned the interviews with multiple individuals within the company: firm level executives (e.g. the 
entrepreneur/founder, vice president, chief executive officer) and at least one member of the management team responsible for R\&D. To limit subject bias, we adopt a courtroom procedure (Eisenhardt, 1989) and asked interviewed individuals to take us step-by-step through a timeline of facts. Only at the second step did we review the chronology and ask informants about I40 through both direct and indirect questions (Bingham \& Eisenhardt, 2011). With at least one of the authors presents, team members were encouraged to correct facts pertaining to the interviews such as timing or outcomes but not why certain events transpired. This technique helped ascertain the facts of each case but allowed freedom in causal attributions.

Questionnaires supporting semi-structured interviews included questions that investigated on both quantitative description and qualitative evaluation of the features of I40. The triangulation made possible by multiple data collection methods, on the one side provide stronger substantiation of constructs and hypothesis (Campbell \& Fiske, 1959) and, on the other, compensated for the weaknesses in each single data collection method by the counterbalancing strengths of another source (Jick, 1979). It was therefore possible to compare information obtained from interviews within the same firm and written records (i.e. financial and technical reports, archives, budget, market and competition reports) (Lee et al., 1999).

Moreover, the combination of both qualitative and quantitative can be highly synergistic because if on the one side qualitative data (i.e. interviews) are necessary for understanding the rationale, on the other side quantitative data can reveal relationships which may be not salient to the researcher or can keep the researcher from being carried away by false impressions in an interview (Eisenhardt, 1989).

As previously stated, because firms may differ in their capability development based on position in the production chain of a HT industry, we selected firms representing each position in the entire chain (Brondoni, 2015). Overall, we collected data from seven semi-structured interviews (i.e. SEI Laser, three suppliers and three customers).

\section{Results}

\subsection{Preliminary Finding: Industry and Firm Description}

"Since 1982 SEI Laser has been one of the most dynamic and innovative companies in the world of laser technology. Due to the complete range of laser systems developed by its $R \& D$ department, it can satisfy the application needs of customers (i.e. value offer) in both vertical and horizontal markets, including: lighting, visual communication, graphic arts, paper converting, labelling, flexible packaging, folding carton, fashion, interior design, furnishing, automotive, engineering and electronics. All SEI Laser systems use ICARO proprietary software which operates on Windows ${ }^{\mathrm{TM}}$ platform, making them easy to interface with the most evolved CAD-CAM versions on the market. SEI Laser has many prestigious customers and industrial partners who it assists with in-depth knowledge giving them innovative solutions which are often specific, and which give significant performances as far as cost, efficiency and quality of the final, generating value creation. For example, the solutions for digital converters are 
represented by high-performing systems and a philosophy of modularity on flexible, expandable and upgradable platforms; thus, they can be suitable for different production needs with commercial, labelling and packaging solutions. Thanks to its technological advances, the converter has revolutionized the laser's opportunity for growth and development: let's consider the laser as a digital instrument in a modern production process where the web to market is an easy goal to reach. SEI Laser not only supplies worldwide customers with products, but also offers integrated application-specific solutions to help them find new opportunities for growth and development (i.e. value capture)." (Entrepreneur).

\subsection{How SEI Laser Perceived the I40 Phenomenon and how it Redefines its Business Model}

"Industry 4.0 is a technological evolution that spans the productive sectors and dictates new manufacturing needs, the flow of communication and the analysis of the process. It is not a specific product, but a new philosophy of integration and communication between machines, systems and the computing cloud. SEI Laser long ago adopted technological choices that meet the new requirements. However, it is now necessary to carry out a new adaptation of the machines to enhance and facilitate the access to the features required by the current technological trends." (Entrepreneur).

$\square$ "For SEI Laser, I40 means making machines capable of collecting and processing data without interruptions within the production chain and with the clear aim of improving the assistance process, even remotely, and covering the needs of customers (i.e. value offer)." (Entrepreneur).

It is impossible to indicate a precise date in which the company started the reorganization of its business model, accepting the inputs coming from I40. It was a slow process started with the digitalization of the tools machine in the early $90 \mathrm{~s}$. At that time, the management of the company understood the potential and the usefulness of making the machines more integrated along the network to the customer (i.e. value capture) and, consequently, they started working to improve the design, oriented in the direction of having interconnected machines, able to save data and to do preventive analysis. The purpose of those activities was (and is) to create value for customers through the collection of data with the aim to improve customer assistance, even remotely (i.e. value offer). It was at that moment that the management started to consider the machines as an integral part of a production workflow, able to dialogue with the production systems of multiple suppliers of the same client of the company. This change led to the need for new skills as testers or for doing assistance in the production process (i.e. value creation). Training courses on IT and data processing were carried out to adapt skills. Currently, both internal and external management of production are coherent with I40. Also, outside the 
company, SEI Laser operates coherently with I40 because the machines have access to the data of the actors present in the production chain.

These innovations have allowed SEI Laser to gain advantages compared to competitors who have continued to produce machines that are not integrated into the production workflow and therefore have not seized the opportunities of the I40 in a timely manner. From the early 2000s through the present, SEI Laser has been considered a leader regarding network and remote control of equipment, despite being a follower in the aspects of using cloud and data analysis tools. Summarizing, Table 1 identifies I40 implications and benefits for SEI Laser in terms of value creation and value capture.

Table 1: I40 Implication and Benefits for SEI Laser

\begin{tabular}{|c|c|}
\hline VALUE CREATION & VALUE CAPTURE \\
\hline $\begin{array}{l}\text { High demanding accuracy [High } \\
\text { demand for accuracy?] }\end{array}$ & Labor productivity increases up to $40 \%$ \\
\hline New diagnostic capabilities & $\begin{array}{l}\text { Improved technical capability for laser } \\
\text { process }\end{array}$ \\
\hline Flexi concept and working modes & Improved reliability \\
\hline $\begin{array}{l}\text { Extremely high geometrical accuracy } \\
\text { and stability }\end{array}$ & $\begin{array}{l}\text { New galvo tuning algorithms for } \\
\text { improved dynamics }\end{array}$ \\
\hline \multirow[t]{3}{*}{ High demand for productivity } & $\begin{array}{l}\text { Higher focus resolution due to new } \\
\text { motor for area selection }\end{array}$ \\
\hline & $\begin{array}{l}\text { Improved capabilities and performances } \\
\text { due to new electronic board }\end{array}$ \\
\hline & Remote cutting accuracy \\
\hline
\end{tabular}

Source: Our elaboration, 2018

\subsection{How SEI Laser Behaves with their Suppliers in Result of I40}

The suppliers are classified into three categories: strategic, order-based and components.
$\square$ "The strategic suppliers are located all over the world, while the other two categories are chosen according to geographical proximity. The strategic suppliers provide the data necessary to understand the progress of the entire sector in which they operate. SEI Laser's relationship with the strategic suppliers was influenced by the I40 because it allowed the acquisition of data in a direct, simple and complete way. Moreover, the language was standardized, which allowed the company to acquire more information through shared protocols. For the ordered-based and component suppliers, the I40 was not relevant." (Entrepreneur).

The interviews indicate that a non-disruptive process exists because SEI Laser has long since adopted technological choices that make existing machines at least predisposed to the requirements of this new philosophy (i.e. I40). Finally, through the I40, the relationships with suppliers have increased from a technical point of view as has the interchange of technical reports, changing the value creation and value offer 
of their BM. So the number of relationships with suppliers and the quality of these relationships has increased.

\subsection{How SEI Laser Behaves with their Customers as a Result of I40}

SEI Laser customers are located all over the world. They are classifiable as follows.

$\square$ "Standard customers not customized. They use laser machines to do various kinds of jobs, such as cutting or engraving. In this group, the impact of the I4O on the BM was not significant, even though preventive or remote maintenance was improved. In fact, these are customers for whom a profitable two-way information exchange has been created. At the present, the main problem is the lack of a common language, even if, thanks to the new technologies labelled I40, all the machines talk to each other. This is a new opportunity that will require new activities of brainstorming among all the actors in the supply chain with the aim of reaching a standard language for the productive sector and the suppliers' chain.” (SEILaser).

$\square$ "Customers who place the machine in a highly digitized work flow. For this category of customers, the I40 is decisive and has been disruptive as they had to create an 140 workflow. The choice regarding when to create the new work flow (i.e. innovation) has depended on the production lines but it has been disruptive in any case. For SEI Laser, the BM changed." (SEILaser).

$\square$ "Customers for which the machine is only partially inserted within the digitized process. This is an intermediate case, characterized by the peculiarities of both previous categories." (SEILaser).

Finally, results from the interviews suggest that I40 may prove to be a disruptive process for one category, yet continuous for another, and inexistent for yet another. In general, for I40 the following are true:

-while I40 touches all the productive sectors, not all customers are ready to innovate, and they experience disruption in the face of the I40 challenge;

-I40 dictates new functional, communicative and process analysis needs;

-I40 heralds a new philosophy of integration and communication between: machines, systems of process (i.e. software), cloud data, cloud computing.

\section{Discussion and Conclusions}

Previous literature states that $\mathrm{I} 40$ is expected to represent a paradigm change for business bearing strong effects in manufacturing processes and competitive advantage. Many authors profess that such impact is manifested in the disruption of traditional incumbents and in enabling the re-organization of production processes where applications of Information and Communication Technologies, Artificial Intelligence and Operational Technologies enable smart, self-organizing distributed systems within factories. What we found is that this is not always true. We found that 
it depends on the position of the SME in the production chain. Therefore, there are firms that face increasing pressure to change, while others must simply adapt or evolve in step by step fashion. In the latter case, we argue that I40 does not represent a true revolution, but an incremental process, granted in high tech industry, that derives from a former revolution or change (Figure 1).

Figure 1: I40 evolution and disruption

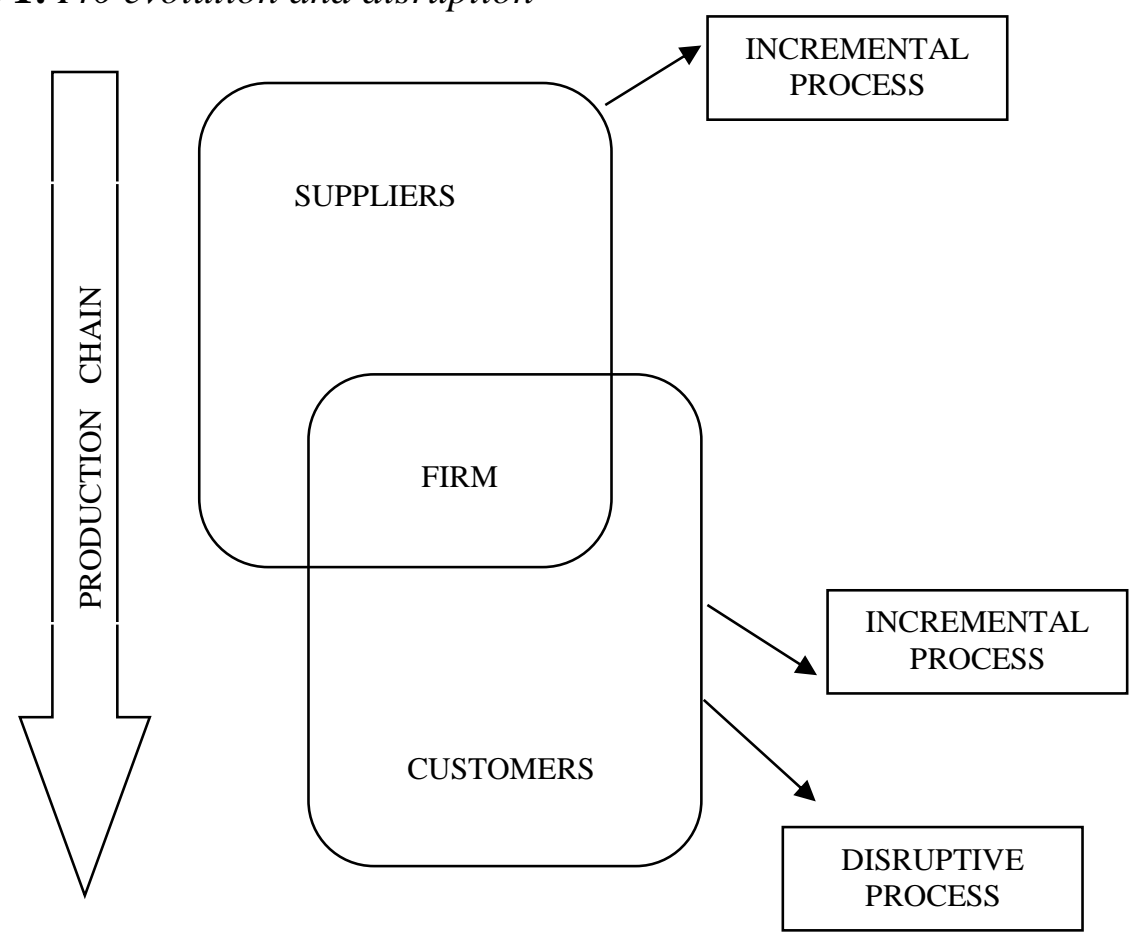

Source: Our elaboration, 2018

The case study in high tech industry is a way to augment the awareness of scholars on the main implications of the transition to an Industry 4.0 paradigm along the entire production chain. The goal of our paper was to contribute with exploratory insights toward a better understanding of how the fourth industrial revolution impacts on the way SMEs business models are being designed, implemented, and supported specifically in the high-tech industry. First, we identified the characteristics of the business model in such industry. Second, we hypothesized the impact of I40 on the business model following an explorative case. Our observations confirmed that the business model is critical for firm performance and must be adapted to the change especially in times of I40. To follow this goal, firms need to update their competencies particularly within the relationships of the production chain.

Based on these evidences, we want to summarize the reasons why I40 is also an evolutionary process. SMEs have been successfully supplying business partners with OEM (original equipment manufacturer) systems for years (D'Allura et al., 2012). Where there were no opportunities to market directly, SEI Laser managed to build up strategic partnerships with important companies, and to start a long-lasting profitable business by sharing its knowledge, strengths and presence within the market. It has also exploited synergies and achieved important goals which could not have been achieved in any other way. Trust, respect and mutual esteem have always been rewarded with important and continually renewed long-term relationships. 
Conversely, the reasons that customers experience I40 as a disruptive process is that SEI's R\&D team is not only a strategic internal resource, but also a support for customers in the development of new products and processes (Brondoni, 2014). In the new scenario, innovation is a process that requires cooperation among different actors, both inside and outside the firm, including suppliers and customers. In Italy, like all over the world, SMEs endeavor, with constructive and cooperative spirit, to meet all customers' demands.

Suppliers can be distinguished as strategic or non-strategic, the first type being those who provide and use a lot of data on the machinery and on the process itself. Strategic suppliers do not need to be necessarily localized close to the producer and may in fact be part of a worldwide network.

Another important aspect to consider is the necessity to acquire new competencies and to invest in human capital. To use the novel opportunities offered by new methods of production properly, the SME needs employees with digital skills of a high level. This is one of the biggest challenges that companies need to face with the I40.

Our work is not free from limitations. First, future research should look at other sectors to verify whether the disruptive impact is the same. Second, we observed the slow change in the BM of SEI Laser facing the suppliers and then the customers. This is strictly related to the characteristics of the product. Moreover, it is not generalizable to the low-tech industry where time will likely pass before I40 becomes part of the manufacturing process. Future research should analyze this aspect as well.

\section{Bibliography}

Arnold, C., Kiel, D. \& Voigt, K. I. (2016). How the Industrial Internet of Things Changes Business Models in Different Manufacturing Industries, International Journal of Innovation Management, 20(08), 1640015. https://doi.org/10.1142/S1363919616400156

Baden-Fuller, C. \& Haefliger, S. (2013). Business Models and Technological Innovation, Long Range Planning, 46(6), 419-426. https://doi.org/10.1016/j.lrp.2013.08.023

Bannò M., Morandi V. \& Amorim Varum C. (2014a). Public Policy for Innovation and Internationalization: Are they Worth it?, Applied Economics Letters, 20(10), 927-930. http://dx.doi.org/10.1080/13504851.2013.765535

Bannò M., Piscitello L. \& Amorim Varum C. (2014b). The Impact of Public Support on SMEs' Outward FDI: Evidence from Italy, Journal of Small Business Management, 52(1), 22-38. http://dx.doi.org/10.1111/jsbm.12029

Bingham, C. B. \& Eisenhardt, K. M. (2011). Rational Heuristics: the 'Simple Rules' that Strategists Learn from Process Experience, Strategic Management Journal, 32(13), 1437-1464. https://doi.org/10.1002/smj.965

Bouncken, R. B. \& Fredrich, V. (2016). Good Fences Make Good Neighbors? Directions and Safeguards in Alliances on Business Model Innovation, Journal of Business Research, 69(11), 5196-5202.

https:// doi.org/10.1016/j.jbusres.2016.04.112

Brondoni, S. M. (2014). Innovation and Imitation for Global Competitive Strategies. The Corporation Development Models of US, Japan, Korea, and Taiwan, Symphonya. Emerging Issues in Management (symphonya.unimib.it), (1) 12-27. http://dx.doi.org/10.4468/2013.1.02brondoni

Brondoni, S. M. (2015). Global Networks, Outside-In Capabilities and Smart Innovation, Symphonya. 
Emerging Issues in Management (symphonya.unimib.it), (1), 6-21. http://dx.doi.org/10.4468/2015.1.02brondoni

Cappiello, G. (2016). Entrepreneurship, Local Growth and Global Markets, Symphonya. Emerging Issues in Management (symphonya.unimib.it), (3), 8-18. http://dx.doi.org/10.4468/2015.3.02cappiello

Dasilva, C. M. \& Trkman, P. (2014). Business Model: What It Is and What It Is Not, Long Range Planning, 47(6), 379-389. https://doi.org/10.1016/j.1rp.2013.08.004

D'Allura, G., Galvagno M. \& Mocciaro Li Destri A. (2012). Regional Systems of Innovation: a Literature Review, Business System Review, 1(1), 139-156.

D’Allura, G. (2015). Data Collection Protocol in Strategic Management Research, Research Methods for Strategic Management, 311.

Eisenhardt, K. M. (1989). Building Theories from Case Study Research, Academy of Management Review, 14, 532-550. https://doi.org/10.2307/258557

Eisenhardt, K. M. \& Graebner, M. E. (2007). Theory Building from Cases: Opportunities and Challenges, Academy of Management Journal, 50,(1), 25-32. https://doi.org/10.5465/amj.2007.24160888

Fabiani S., Schivardi F. \& Trento S. (2005). ICT Adoption in Italian Manufacturing: Firm-Level Evidence, Industrial and Corporate Change, 14, (2), 225-249. http://dx.doi.org/10.1093/icc/dth050

Ghauri, P. \& Grønhaug, K. (2002). Research Methods in Business Studies: A Practical Guide, Financial Times and Prentice-Hall, Harlow, UK.

Jick, T. D. (1979). Mixing Qualitative and Quantitative Methods: Triangulation in Action, Administrative Science Quarterly, 24,(4), 602-611.

Kagermann, H., Helbig, J., Hellinger, A. \& Wahlster, W. (2013). Recommendations for Implementing the Strategic Initiative INDUSTRIE 4.0: Securing the Future of German Manufacturing Industry; Final Report of the Industrie 4.0 Working Group.

Lee, T. W., Mitchell, T. R. \& Sablynski, C. J. (1999). Qualitative Research in Organizational and Vocational Psychology, 1979-1999, Journal of Vocational Behavior, 55, (2), 161-187. http://dx.doi.org/10.1006/jvbe.1999.1707

Massa, L., Tucci, C. \& Afuah, A. (2017). A Critical Assessment of Business Model Research, Academy of Management Annals 11 (1), 73-104. https://doi.org/ 10.5465/annals.2014.0072

Miles, M. B. \& Huberman, M. (1994). Qualitative Data Analysis: An Expanded Sourcebook, Sage Publications, Thousand Oaks, CA.

Mokyr J. (1997). Are we Living in the Middle of an Industrial Revolution? , Federal Reserve Bank of Kansas City Economic Review, Second Quarter, 31-43.

Osterwalder, A., Pigneur, Y. \& Tucci, C. L. (2005). Clarifying Business Models: Origins, Present, and Future of the Concept, Communications of the Association for Information Systems, 16(1), 1. http://aisel.aisnet.org/cais/vol16/iss1/1

Pauwels, P. \& Matthyssens, P (2004). The Architecture of Multiple Case Study Research in International Business, Rebecca Marschan-Piekkari and Catherine Welsh (Eds.), Handbook of Qualitative Research Methods for International Business, Edward Elgar Publishing, Cheltenham.

Pironti, M., Cautela, C. \& Christodoulou J. (2015). Business Models Innovation Thorough New Customers Roles: A Design-Driven Case Study, Symphonya. Emerging Issues in Management (symphonya.unimib.it), (2), 25-41. http://dx.doi.org/10.4468/2015.2.03pironti.cautela.christodoulou

Porter, M. E. \& Heppelmann, J. E. (2014). How Smart, Connected Products are Transforming Competition, Harvard Business Review, 92(11), 64-88.

Radziwon, A., Bilberg, A., Bogers, M. \& Madsen, E. S. (2014). The Smart Factory: Exploring Adaptive and Flexible Manufacturing Solutions, Procedia Engineering 69, 1184-1190. https://doi.org/10.1016/j.proeng.2014.03.108

Rieple A. \& Pisano P. (2015). Business Models in a New Digital Culture: The Open Long Tail Model, Symphonya. Emerging Issues in Management (symphonya.unimib.it), (2), 13-23. http://dx.doi.org/10.4468/2015.2.06rieple.pisano

Rudtsch, V., Gausemeier, J., Gesing, J., Mittag, T. \& Peter, S. (2014). Pattern-based Business Model Development for Cyber-Physical Production Systems, Procedia CIRP, 25, 313-319. 
https://doi.org/10.1016/j.procir.2014.10.044

Schmidt, R., Möhring, M., Härting, R. C., Reichstein, C., Neumaier, P. \& Jozinović, P. (2015). Industry 4.0-Potentials for Creating Smart Products: Empirical Research Results, In International Conference on Business Information Systems (pp. 16-27), Springer, Cham. https://doi.org/10.1177/2158244016653987

Spieth, P. \& Schneider, S. (2016). Business Model Innovativeness: Designing a Formative Measure for Business Model Innovation, Journal of Business Economics, 86(6), 671-696. https://doi.org/10.1142/S136391961340001X

Strauss, A. \& Corbin, J. (1998). Basics of Qualitative Research, SAGE, Thousand Oaks, CA.

Teece, David J. (2010) Business Models, Business Strategy and Innovation. Long Range Planning, 43(2-3), 172-194. https://doi.org/10.1016/j.lrp.2009.07.003

Trento, S. (2005). Corporate Governance and Industrial Relations in Italy, Corporate governance and labour management: An international comparison, 226-53. http://dx.doi.org/10.1093/acprof:oso/9780199263677.003.0009

Tresca, R. (2013). Global Business Networks and Competitiveness of SMEs, Symphonya. Emerging Issues in Management (symphonya.unimib.it), Issue 2, 67-78. http://dx.doi.org/10.4468/2013.2.05tresca

Yin, R. K. (1984). Case Study Research: Designs and Methods, SAGE, London.

Yin, R. K. (2003). Case Study Research (3rd ed.), SAGE, London.

Zott, C. \& Amit, R. (2010). Business Model Design: an Activity System Perspective, Long Range Planning, 43(2-3), 216-226.

https://doi.org/doi:10.1016/j.1rp.2009.07.004 